\title{
Value of contrast-enhanced multidetector computed tomography in imaging of symptomatic patients after laparoscopic Roux-en-Y gastric bypass and laparoscopic sleeve gastrectomy
}

\author{
Reem Hassan Bassiouny ${ }^{*}$ (iD and Nivine abdel Moneim Chalabi
}

\begin{abstract}
Background: To assess the role of contrast-enhanced multidetector computed tomography (MDCT) in the assessment of symptomatic patients following laparoscopic Roux-en-Y gastric bypass and laparoscopic sleeve gastrectomy.
\end{abstract}

Results: We reviewed the studies of 129 cases and found complications in 113 patients: 55 early complications and 48 late complications. All of these complications were diagnosed with intravenous contrast-enhanced MDCT. Statistically significant difference was found between UGIS and MDCT in the diagnosis of many cases.

Conclusion: The rate of complications in bariatric surgery is high and the associated mortality is not negligible. The interpreting radiologists should know the normal postoperative findings and be aware of possible complications.

Keywords: Contrast-enhanced multidetector computed tomography, Laparoscopic Roux-en-Y gastric bypass, Laparoscopic sleeve gastrectomy

\section{Background}

Obesity is a serious, multifactorial, chronic illness that is associated with multiple medical comorbidities and an increase in early mortality $[1,2]$. The prevalence of obesity has increased worldwide to epidemic proportions in both developed and developing countries over the past 30 years [3]. Morbid obesity has been defined as body mass index (BMI) greater than $40 \mathrm{~kg} / \mathrm{m}^{2}$ or greater than or equal to 35 $\mathrm{kg} / \mathrm{m} 2$ in patients who have some comorbidity $[4,5]$. Obesity treatments, such as medications, exercise, and diet modifications, do not usually provide long-standing results; thus, bariatric surgery, either restrictive or mixed restrictive and malabsorptive techniques, became a well-accepted treatment option worldwide [6]. Surgery can provide a sustainable long-term option for weight loss [7], reduce the associated comorbidity, and provide correction of metabolic

\footnotetext{
* Correspondence: rhbassiouny1592@gmail.com

Radiodiagnosis Department, Ain Shams University, Cairo, Egypt
}

disorders, reduction of cardiovascular risk, and improvement of the quality of life $[8,9]$.

Laparoscopic Roux-en-Y gastric bypass is the most popular bariatric procedure performed in the USA because it is associated with greater sustained weight loss and higher long-term success rates than other forms of bariatric surgery $[10,11]$. It was originally introduced in the 1960s and 1970s by Griffen [12] and uses a combination of restriction and malabsorption procedures. Roux-en-Y gastric bypass entails the use of a staplercutter device to create a staple line that divides the stomach into a small fundal component around $15 \mathrm{cc}$ (i.e., the gastric pouch) and a much larger excluded component (i.e., the excluded stomach). After this, one jejunal loop is cut off at 25 to $50 \mathrm{~cm}$ distal to the ligament of Treitz, and its distal edge is brought up and anastomosed to the gastric pouch by means of an end-to-end or, more commonly, an end-to-side gastrojejunal anastomosis [13-15]. This is the restrictive part of the RYGB 
Table 1 The sociodemographic variables and BMI

\begin{tabular}{llll}
\hline & Gender & Age & BMl \\
\hline LSG $(N=84)$ & Female (66\%) & Mean \pm SD $=40.38 \pm 7.11$ & Mean \pm SD $=46.56 \pm 6.27$ \\
& Male (34\%) & Range $=25-59$ & Range $=35-58$ \\
RYGB $(N=45)$ & Female (78\%) & Mean \pm SD $=43.35 \pm 7.63$ & Mean \pm SD $=47.98 \pm 5.76$ \\
& Male (22\%) & Range $=27-60$ & Range $=39-60$ \\
$P$ value & 0.479 & 0.572 & 0.254 \\
\hline
\end{tabular}

and that limb is called the alimentary/efferent limb and can be placed in an ante or retro-gastric approach. The remnant stomach, duodenum, and proximal jejunum make the biliopancreatic/afferent limb which becomes then attached to the alimentary limb via a jujeno-jujenal anastomosis at approximately $75-150 \mathrm{~cm}$ distal to the gastrojejunostomy.

Laparoscopic sleeve gastrectomy is a relatively recent surgical technique first introduced in 1999 [16]. It gained popularity among bariatric surgeons due to its simple technique and lower risk profile [17]. It is performed by laparoscopically dividing the stomach along its long axis and resecting the greater curvature of the fundus, body, and proximal antrum, producing a narrow, banana-shaped gastric pouch along the lesser curvature [14]. The remaining stomach has a residual volume of only about $100 \mathrm{ml}$, promoting weight loss by causing the patient to experience early satiety by means of the restrictive effect of the pouch [10-19]. Although complications due to bariatric surgery are growing thin, all practicing radiologists should be familiar with these complications because by early diagnosis and intervention, patient morbidity and mortality might be reduced $[18,19]$.
Abdominal pain/discomfort, obstructive symptoms, and hemodynamic instability are the most common complaints following GBP and LSG with highly variable clinical presentation $[20,21]$. In the early postoperative period, patients may develop epigastric and postprandial abdominal pain due to maladaptive eating behavior and food intolerance. Constipation is common in the early postoperative period and is usually characterized by diffuse and crampy lower abdominal pain [22]. Esophageal motility disorders may cause pain after bariatric surgery that is typically substernal in location. Postoperative abdominal pain may also result from biliary causes such as cholelithiasis producing right upper quadrant abdominal pain after GBP and sleeve gastrectomy. Marginal gastric ulceration has been reported as one of the more common complications, ranging from 1 to $16 \%$ [23-26] in GBP patients generally presenting with burning epigastric pain often immediately postprandial [22]. Anastomotic leak and gastro-gastric fistula which communication between the gastric pouch and the remnant stomach in GBP patients can cause abdominal pain at the time of leakage [27, 28]. Other presenting symptoms can be fever and tachycardia along with nausea, vomiting, fatigue, and diarrhea [29],

Table 2 Complications of Roux-en-Y gastric bypass

\begin{tabular}{|c|c|c|}
\hline & Complications and radiographic findings & Management \\
\hline \multirow[t]{2}{*}{$\begin{array}{l}\text { Early postoperative } \\
(n=5)\end{array}$} & $\begin{array}{l}\text { Leaks }(n=2):(5.7 \%) \text {; within } 2-4 \text { days } \\
\text { (Figs. } 2 \text { and } 3) \text { ) } \\
\text { Leakage was at the site of gastrojejunal anastomosis }\end{array}$ & $\begin{array}{l}\text { Percutaneous drainage by pigtail catheter } \\
\text { and insertion of naso-enteric tube. }\end{array}$ \\
\hline & $\begin{array}{l}\text { Perigastric collection and hematoma }(n=3) \text { : }(8.6 \%) \\
\text { within } 3-7 \text { days (Fig. } 1)\end{array}$ & $\begin{array}{l}\text { The small collection was treated conservatively } \\
\text { and the large collection was managed by } \\
\text { gastro-jejunostomy }\end{array}$ \\
\hline \multirow[t]{7}{*}{ Late postoperative $(n=30)$} & Gatrojujenostomy anastomotic stricture $(n=1)$ & Endoscopic dilation of the stricture \\
\hline & $\begin{array}{l}\text { Internal hernia ( } n=14)(40 \%) \text { : } 2-4 \text { years (Fig. 4) } \\
\text { Altered disposition of loops and anastomosis } \\
\text { Twisting of mesenteric vessels (whirl sign) } \\
\text { Dilated bowel loops with mushroom appearance } \\
\text { of the distended loops in the left hypochondrium } \\
\text { Mesenteric fat planes densification }\end{array}$ & Medical treatment (case 6) \\
\hline & $\begin{array}{l}\text { Intestinal obstruction }(n=6)(17 \%): 2-4 \text { years } \\
\text { (Fig. 5) }\end{array}$ & Treated by laparoscopy (case 1) \\
\hline & Intussusception ( $n=5$ ) (14.3\%): 2-4 years (Fig. 6) & ( cases 20 and 21) \\
\hline & luminal narrowing $(n=1)$ (2.8\%): 1 year & \\
\hline & $\begin{array}{l}\text { Distended bowel and weight gain }(n=2)(5.7 \%) \text { : } \\
\text { after } 4 \text { years }\end{array}$ & \\
\hline & Gastroesophageal spasm $(n=1)(2.8 \%)$ : 9 months & \\
\hline
\end{tabular}


Table 3 Complications of laparoscopic sleeve gastrectomy

\begin{tabular}{|c|c|c|}
\hline & Complications and radiographic findings & Management \\
\hline \multirow[t]{2}{*}{ Intraoperative $(n=3)$} & Liver contusion $(n=1)$ & \\
\hline & Splenic tear $(n=2)$ : a serrated low-density area in the spleen & \\
\hline \multirow[t]{5}{*}{ Early postoperative $(n=48)$} & $\begin{array}{l}\text { - Leakage }(n=18) \text { : }(23.1 \%) \text {; within } 1-10 \text { days. (Figs. } 8 \text { and } 9 \text { ) } \\
\text { - The most common site of leak was the proximal } 1 / 3 \text { of the } \\
\text { sleeve just below the esophagogastric junction, followed } \\
\text { by middle then lower thirds } \\
\text { - Pneumoperitoneum } \\
\text { - Free fluid }\end{array}$ & Laparoscopic re-exploration and surgical closure \\
\hline & $\begin{array}{l}\text { Perigastric collection and hematoma }(n=26)(33 \%) \text { within 3-10 } \\
\text { days (Fig. } 7) \\
\text { - Acute hematoma: hyperdense collection } \\
\text { - Hemoperitoneum }(n=5) \\
\text { - Extravasation of IV contrast if there is active bleeding from } \\
\text { staple lines or suture lines }(n=2)\end{array}$ & $\begin{array}{l}\text { Conservative }(n=9) \text { laparoscopic-re-exploration } \\
\text { and surgical drainage in the presence of } \\
\text { hemodynamic instability }(n=3)\end{array}$ \\
\hline & $\begin{array}{l}\text { Gastropancreatic abscess }(n=1) \text { located in the left subphrenic } \\
\text { area (Fig. } 11 \text { ) }\end{array}$ & $\begin{array}{l}\text { CT-guided percutaneous drainage with appropriate } \\
\text { antibiotic coverage }\end{array}$ \\
\hline & $\begin{array}{l}\text { Gastrobronchial fistula ( } n=1 \text { ) } \\
\text { The site of the fistulous tract was clearly visualized by } \subset T\end{array}$ & failed to heal after endoscopic insertion of a stent \\
\hline & Rectus sheath hematoma: $(n=2)$ & \\
\hline \multirow[t]{8}{*}{ Late postoperative $(n=27)$} & $\begin{array}{l}\text { Vascular thrombosis: PV, SMV, and SV }(n=10)(13 \%) \\
\text { within } 6 \text { months to } 2 \text { years postoperatively (Fig. 10) }\end{array}$ & Medical treatment. \\
\hline & Gastric stricture $(n=1)$ (Fig. 12) & $\begin{array}{l}\text { Focal strictures respond to endoscopic dilation, } \\
\text { but longer segments of narrowing necessitate } \\
\text { surgical revision or resection of the pouch }\end{array}$ \\
\hline & $\begin{array}{l}\text { Dilatation of the gastric pouch }(n=8)(10 \%) \text { and } \\
\text { weight gain (Fig. 13) }\end{array}$ & Surgical revision of the pouch \\
\hline & $\begin{array}{l}\text { Incisional hernia }(n=1) \text { : eventration of bowel loops } \\
\text { and mesenteric fat }\end{array}$ & \\
\hline & Hiatus hernia $(n=4)$ & \\
\hline & Gastritis $(n=1)$ & \\
\hline & S.C. seroma $(n=1)$ & \\
\hline & Port site hernia $(n=1)$ & \\
\hline
\end{tabular}
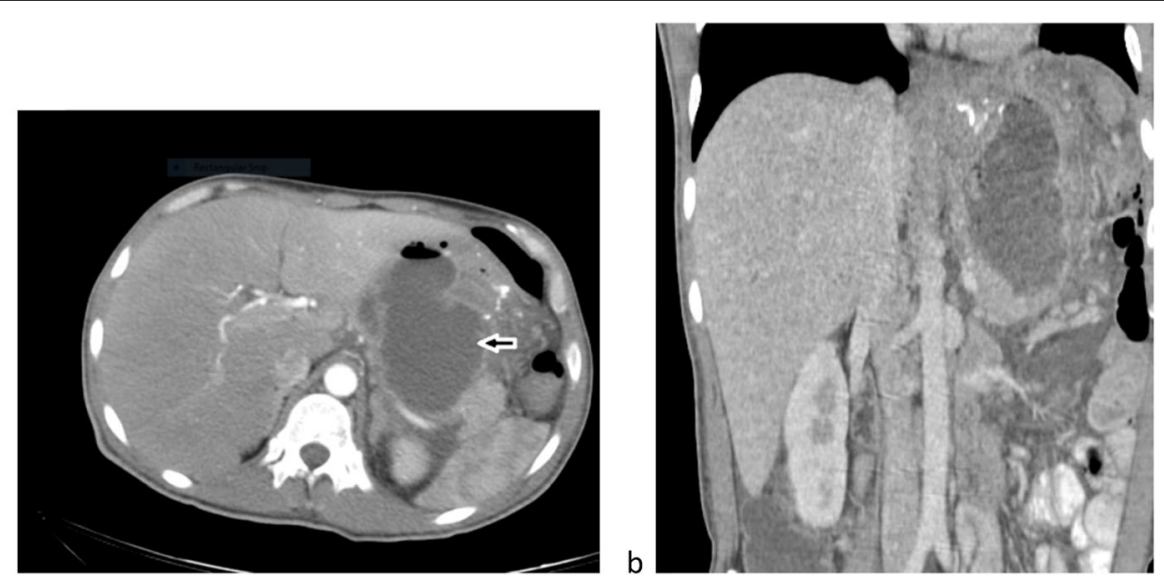

Fig. 1 A thirty-five-year-old male patient presented 5 days post-Roux-en-Y gastric bypass by abdominal pain and fever. a MSCT axial and $\mathbf{b}$ coronal reconstruction images show thick-walled marginally enhancing fluid collection with increased density of the surrounding mesenteric fat planes. MSCT diagnosis, operative bed-infected hematoma 


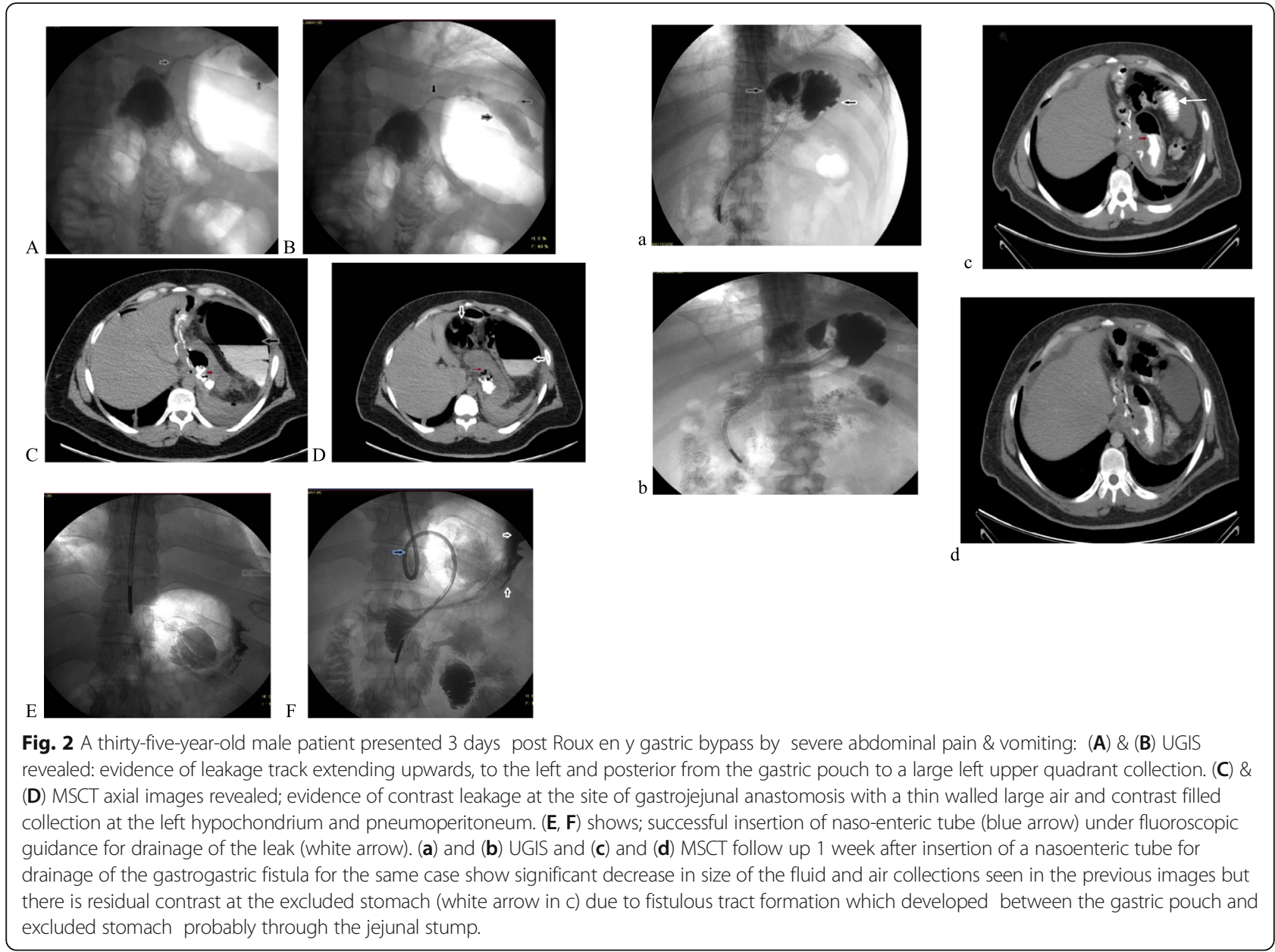

small-bowel-related causes of postoperative abdominal pain include internal hernia, adhesive intestinal obstruction, intussusception, and blind loop syndrome. Internal hernia patients often present with diffuse, episodic, and severe abdominal pain that lasts hours and may or may not be postprandial [22]. Adhesive small-bowel obstruction is thought to occur less in the era of laparoscopy. However, this should always be considered when a patient presents with abdominal pain or vomiting after GBP [30]. Although rare, jejunojejunal intussusception can be a cause of abdominal pain in GBP patients often presenting with upper quadrant abdominal pain. Blind limb syndrome is the enlargement or dilation of the blind limb and can also cause postprandial abdominal pain in GBP patients due to distention [31].

Our aim in this prospective study was to investigate the value of intravenous contrast-enhanced multidetector computed tomography (IVCE-MDCT) in identifying postoperative complications of laparoscopic Roux-en-Y gastric bypass and laparoscopic sleeve gastrectomy in symptomatic patients.

\section{Methods \\ Patients}

This study was conducted at the radiology department of a specialized hospital in the period from December 2014 to March 2018. The study cohort primarily included all patients who underwent laparoscopic gastric bypass and sleeve gastrectomy operated at the bariatric surgery department for treating their morbid obesity $(\mathrm{BMI}>=35$ $\mathrm{kg} / \mathrm{m}^{2}$ ) with obesity-related serious comorbidities (ex. DM, HTN) or BMI > 40 with or without comorbidities. These patients were referred for the diagnostic evaluation of their postoperative complaints in the early and late postoperative periods. Thorough history taking, clinical review, and laboratory investigations were done to rule out nutritional/functional causes of abdominal pain. An upper gastrointestinal imaging (UGI) was performed for all patients. This was followed by CT scans and right upper quadrant ultrasound (when the gallbladder is present). Exclusion criteria included 47 patients who had undergone other surgical techniques or had been operated by a different team, those proved to have functional or 
a

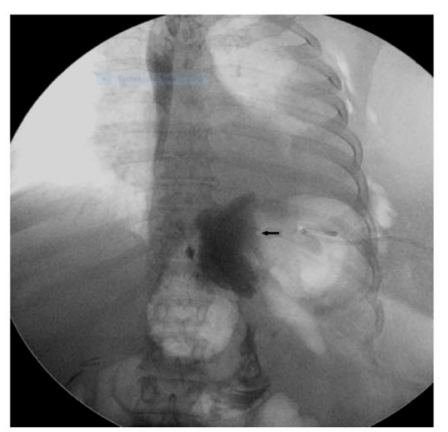

c
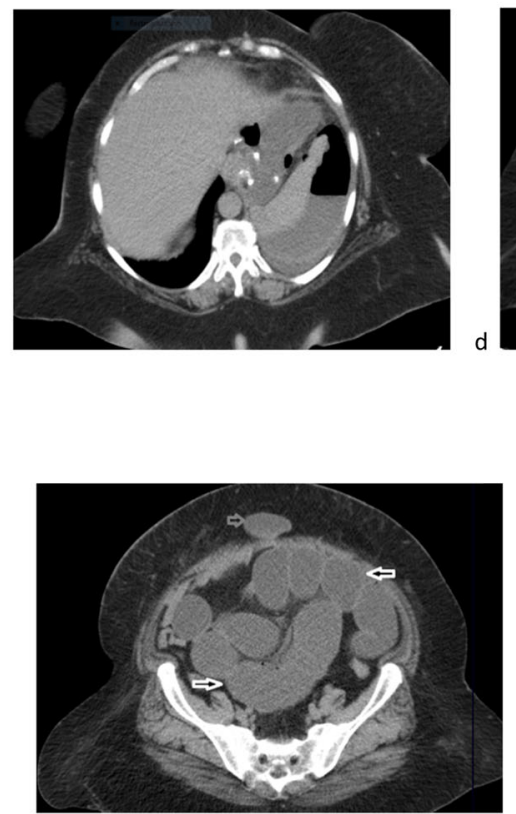

e

Fig. 3 A fifty-six-year-old female patient presented 7 days post-Roux-en-Y gastric bypass by abdominal pain, vomiting, and tachycardia. a, b UGSI shows evidence of leakage (black arrow). c, d Axial MSCT shows evidence of leakage. e, f Axial and coronal reformatted MSCT shows abdominal wall hernia containing fluid-filled small bowel (gray arrow) with dilated small bowel proximally ( white arrow) and collapsed bowel loops distally (intestinal obstruction)

biliary causes of abdominal symptoms as shown by ultrasound, those with contraindications to radiation exposure or iodinated contrast media and those exceeding the weight limit of the examination table $(300 \mathrm{~kg}$ maximum weight capacity). Included patients (a total 129) were interviewed and a protocol was filled with identification of hospital number, name, age, gender, time of surgery, and history of allergy to the iodinated contrast media or drugs.

\section{Technique}

An upper gastrointestinal contrast-enhanced study (UGIS) was first performed for all patients. The choice of contrast medium whether gastrografin or barium was determined by the time of presentation of the patient and his complain. For patients presenting in the early postoperative period (first 30 days after surgery) gastrografin meal was done unless there is any suspicion of aspiration or a fistulous communication to tracheobronchial tree due to the
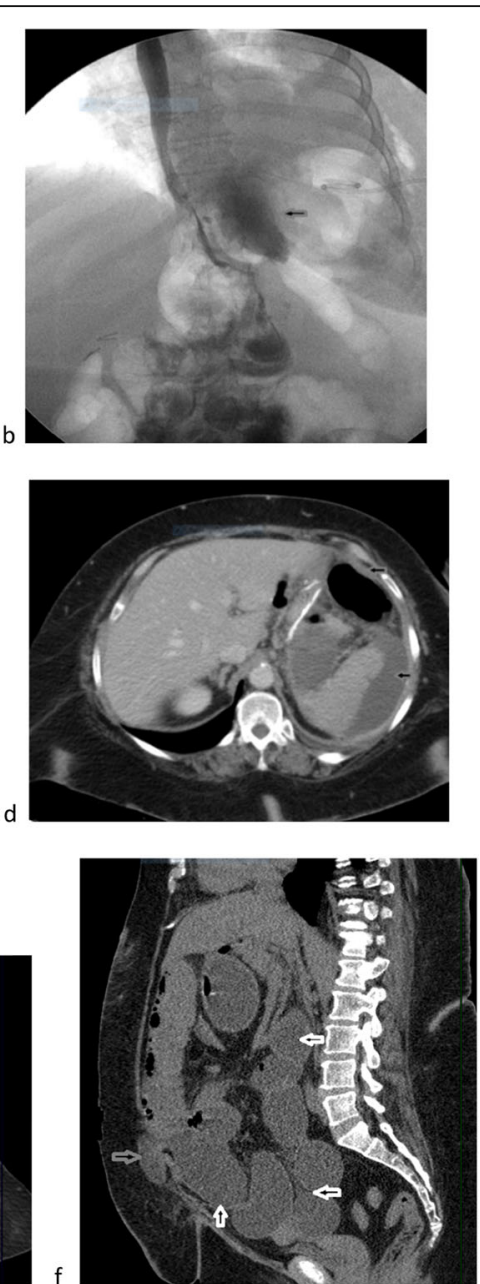

risk of gastrografin-associated pneumonitis. For patients presenting later, barium meal was done unless there is any fear of communication to the mediastinum or to the peritoneal cavity, gastrografin was used instead because of barium's risk of massive peritonitis or mediastinitis. The patients were asked to fast for $6 \mathrm{~h}$ prior to the study. Scout images were obtained to detect free or loculated extraluminal gas as well as radiopaque staple lines that otherwise could be mistaken for small leaks during the fluoroscopic examination. Under fluoroscopic screening the patient was asked to swallow the bolus of the contrast and imaging was performed in the supine and supine left posterior oblique position, screening down the esophagus into the gastric pouch. If leakage was demonstrated across the staple line in RYGB or along the resection line in sleeve gastrectomy the examination was stopped. If no leakage was noticed, rotation from left lateral to RAO to supine until opacification of the duodenum then jejunal loops occurs. In RYGB, the CM is followed from the pouch into 


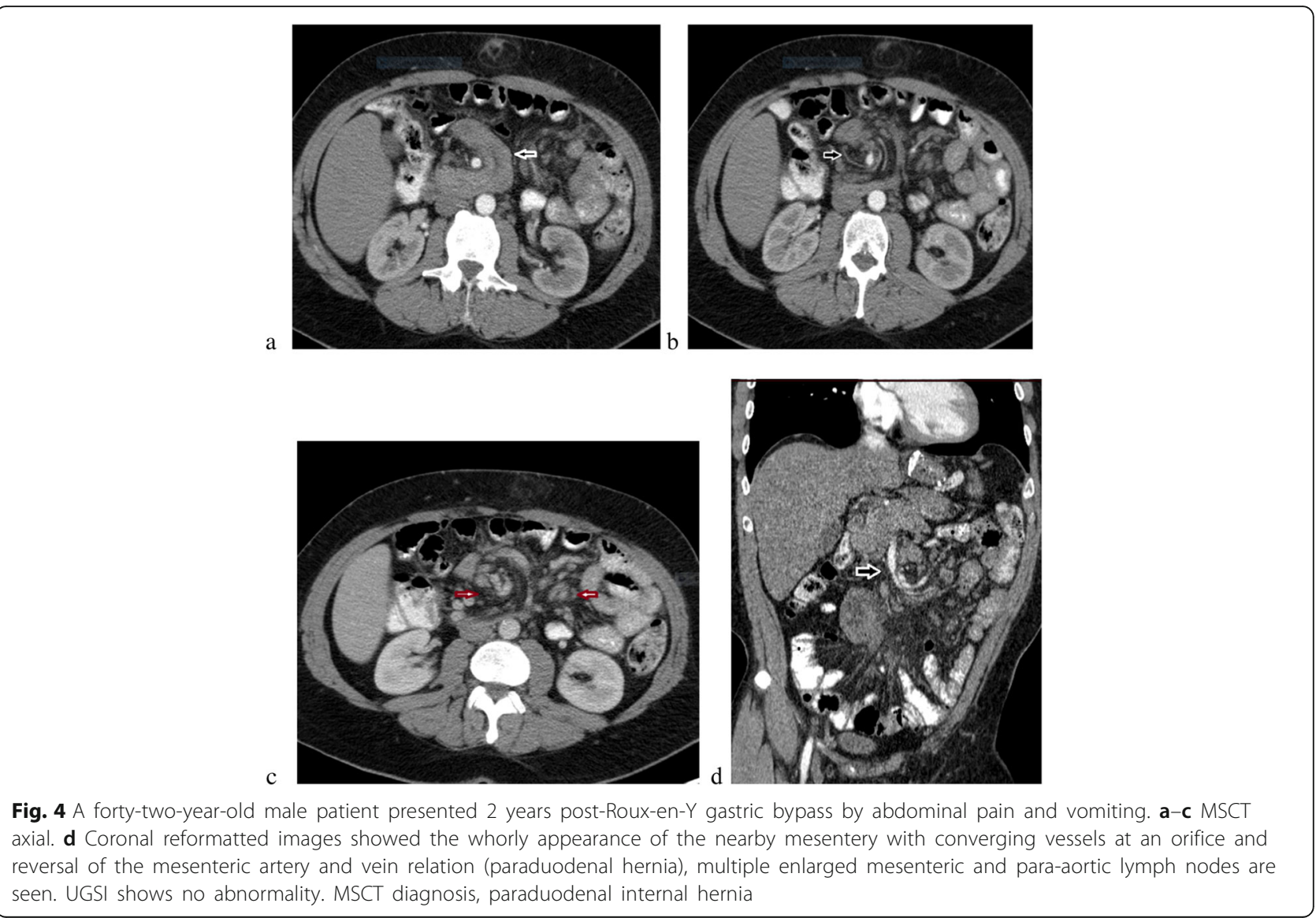

the Roux limb via the gastrojejunal anastomosis. The time taken for complete passage of the contrast through the gastric pouch was calculated (gastric emptying time) and the free passage through the bowel loops was assessed.

For computed tomography, a consent form was delivered to all patients and thoroughly explained. The MDCTs were conducted using 128-MDCT scanner (Toshiba Aquilion) with detector configuration of $128 \times 0.5 \mathrm{~mm}$, rotation time of $0.35 \mathrm{~s}, 120 \mathrm{kV}$, and $93 \mathrm{mAs}$. Axial slices were obtained from the diaphragmatic domes to the lower end of symphysis pubis. Unenhanced scan is performed to detect hemorrhage followed by contrast-enhanced scan after the intravenous injection of Omnipaque at a dose of $150 \mathrm{ml}$, with mechanical pump injectors at $2-3 \mathrm{ml} / \mathrm{s}$ in the arterial,

a
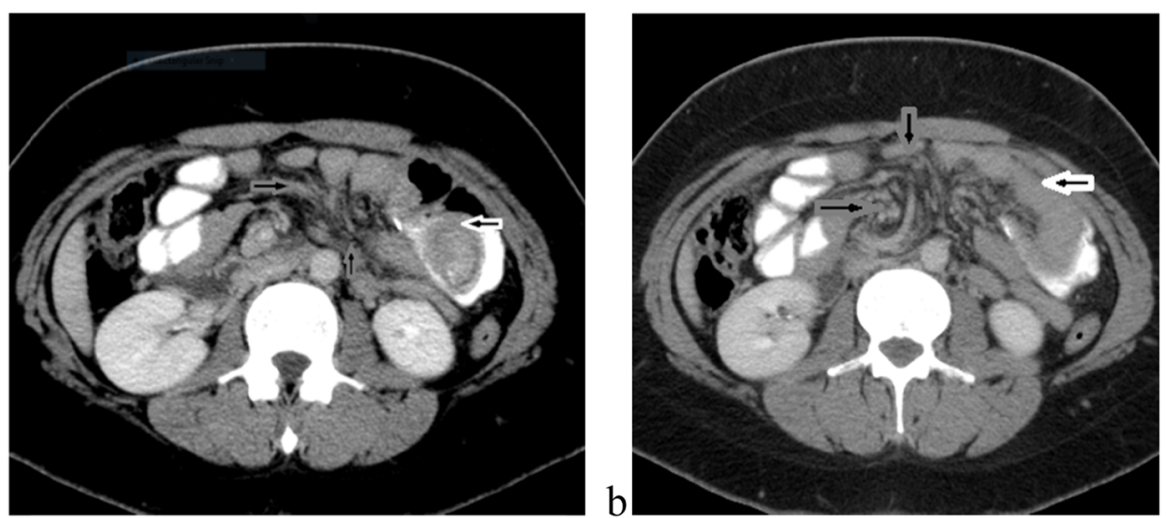

Fig. 5 A thirty-nine-year-old male patient presented 2 years post-Roux-en-Y gastric bypass by abdominal pain and vomiting. a, b Axial MSCT shows dilatation of some of the proximal jejunal loops with a mild thickened wall (white arrow) associated with a right para-central whirling appearance of the mesenteric structures (gray arrow), below the origin of the superior mesenteric artery. Diagnosis: internal hernia with proximal bowel obstruction post-RYGB 
a
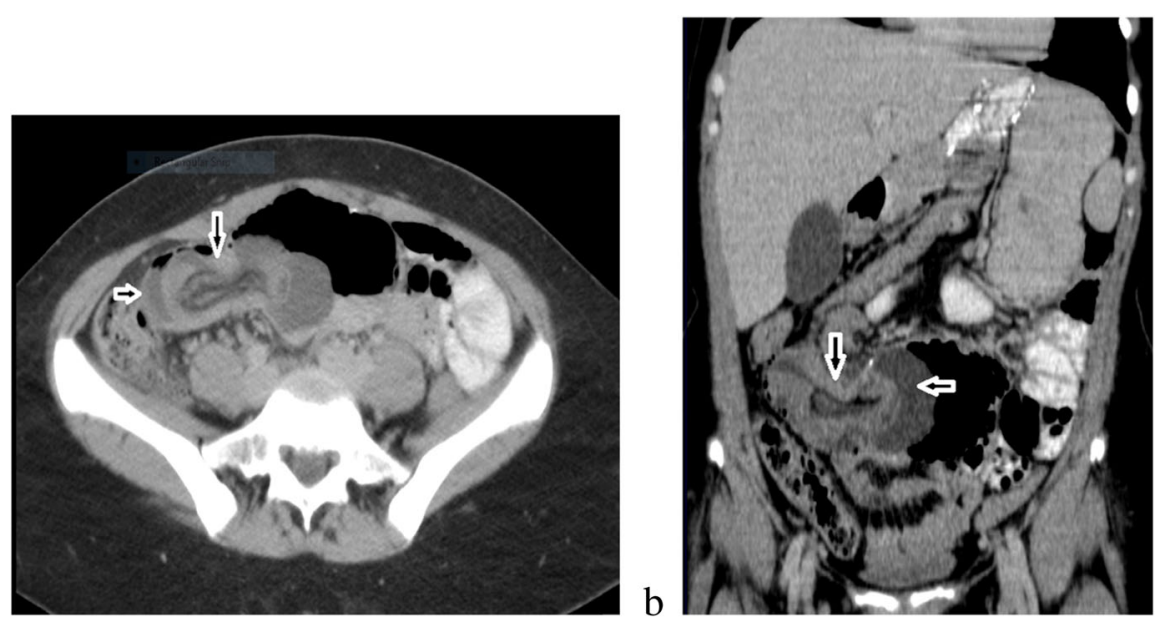

Fig. 6 A thrirty-four-year-old female patient presented 2 years post-Roux-en-Y gastric bypass by abdominal pain and diarrhea. a, b MSCT axial and coronal reconstruction images show complex mass seen at right lower abdominal quadrant ( white arrow) showing edematous bowel loops wall with bowel-within-bowel configuration (target appearance). Small bowel intussusception post-GRYB

portal, and equilibrium phases. The arterial phase is used mainly to identify active bleeding and the portovenous phase to identify an abscess. On suspicion of dehiscence of sutures or perforation, a sequence is then performed after oral intake of iohexol (Omnipaque 300 , Nycomed,
Princeton, NJ, USA, diluted in mineral water for $30 \mathrm{~min}$ ). The volume of administered oral contrast material will depend on the patient's tolerance. Finally, the reconstructed image data set was networked to the workstation. Coronal and sagittal reconstruction was
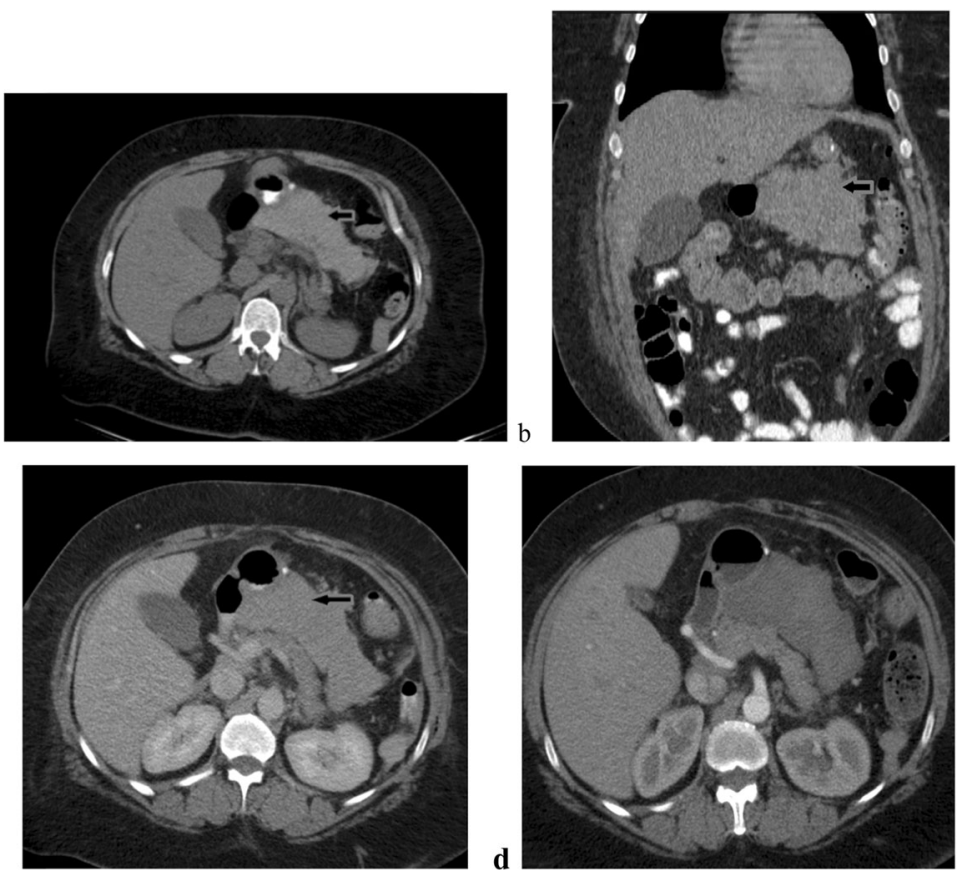

Fig. 7 A thirty-nine-year-old female patient with BMl of $42 \mathrm{~kg} / \mathrm{m}^{2}$ was presented 4 days post-lap. sleeve gastrectomy by abdomen pain and tachycardia. UGS shows no abnormality.a, b MSCT axial and coronal reformatted images revealed a large irregular walled extraluminal highdensity fluid collection at the operative bed with soft tissue stranding of the surrounding fat. $\mathbf{d}$ Follow-up CT after 2 weeks shows a stationary course of the previously depicted operative bed collection. Diagnosis: perigastric hematoma post-LSG 

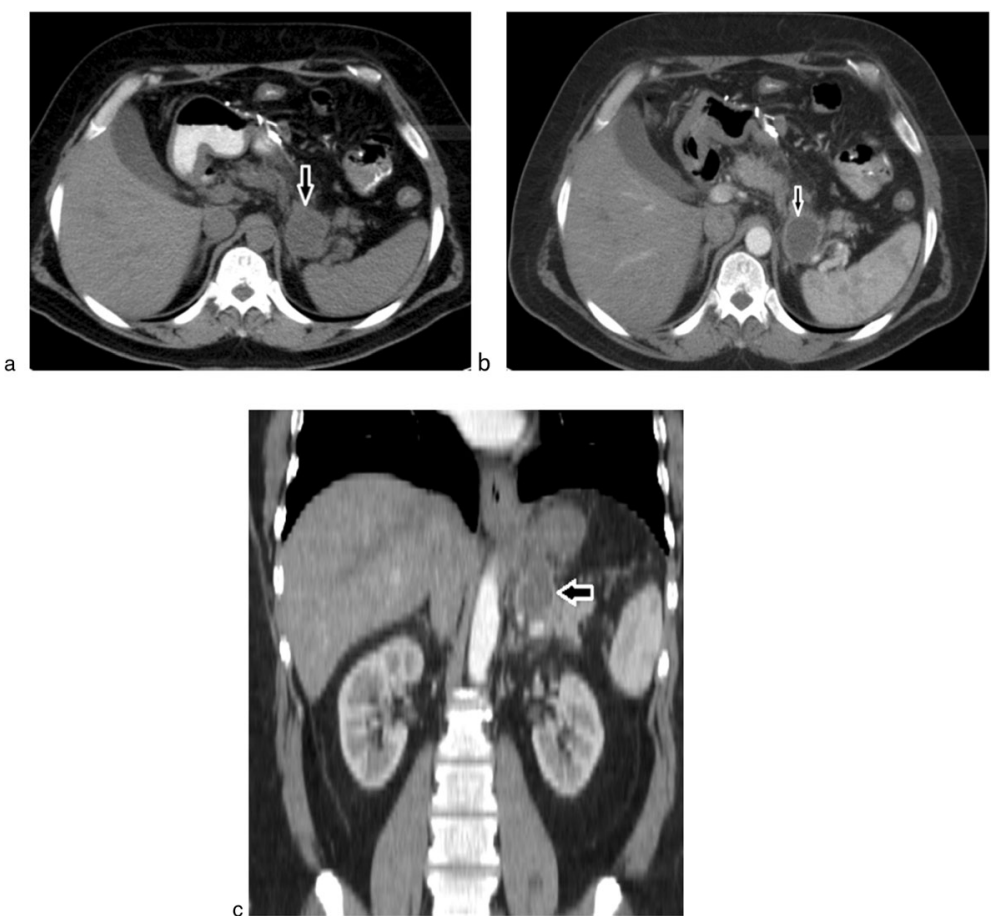

Fig. 8 A forty-three-year-old male patient presented 5 days post-lap. sleeve gastrectomy by severe abdominal pain, fever, and tachycardia. a, b MSCT axial and c coronal reformatted images show a localized collection on the left of the sleeved stomach, adherent to the tail of the pancreas with no obvious clear cleavage plane between them. This collection is associated with surrounding minimal focal mesenteric fat stranding and mural enhancement post-I.V. contrast administration. UGSI shows no abnormality. MSCT diagnosis: peri-gastro-pancreatic abscess

obtained at $2 \mathrm{~mm}$ slice thickness. All studies were reviewed by two radiologists with at least 15 years of experience in abdominal imaging.

\section{Image analysis}

All studies were reviewed by three radiologists with 8 , 15 , and 20 years of experience in gastrointestinal radiology respectively.

\section{In cases of Roux-en-Y gastric bypass}

The anatomy of the postoperative gastric bypass was studied by analyzing the volume of the gastric pouch, proximal aspect of the jejunum efferent loop, the jejunal afferent loop (blind loop), the excluded stomach, and the gastric area. The presence of complications was investigated such as (1) anastomotic leaks; most leaks are defined after oral administration of water-soluble contrast as blind-ending tracks or sealed-off collections abutting the anastomotic region or, less frequently, as free leaks into the peritoneal cavity. Most leaks occur at the gastrojejunal anastomosis [24, 25], less common sites of perforation include the gastric pouch, blindending jejunal stump, and jejunojejunostomy. Anastomotic leaks may extend as extraluminal collections in the left upper quadrant on upper GI studies or CT scans, sometimes continuing superiorly into the subphrenic space $[15,23-25,32]$. (2) gastrojejunal anastomotic strictures. They usually appear on UGIS as short segments of smooth narrowing at the gastrojejunal anastomosis [14]. If obstruction is present, the gastric pouch may be dilated, and emptying of barium into the Roux limb may be delayed with no distension of the distal small intestine and colon. (3) Internal hernia, usually results from herniation of small bowel loops through a defect in the transverse mesocolon (for a retrocolic Roux limb), is a defect in the small bowel mesentery (for a jejunojejunal anastomosis), or a defect posterior to the Roux limb (i.e., Petersen defect). It should be suspected on both CT images and barium studies when a cluster of small bowel loops is seen in abnormal locations especially the left mid-abdomen or left upper quadrant above the transverse mesocolon often displacing other bowel and associated with migration of an anastomotic jejunojejunal suture line. This suture line is most often displaced from its typical location in the left mid-abdomen into the left upper quadrant, but it can also be displaced into the right midabdomen [33]. One advantage of the barium study over CT is the ability to visualize changes in the configuration of the small bowel entering and exiting the hernia during the course of the examination with retention of barium within these loops [26, 33]. However, CT 
a
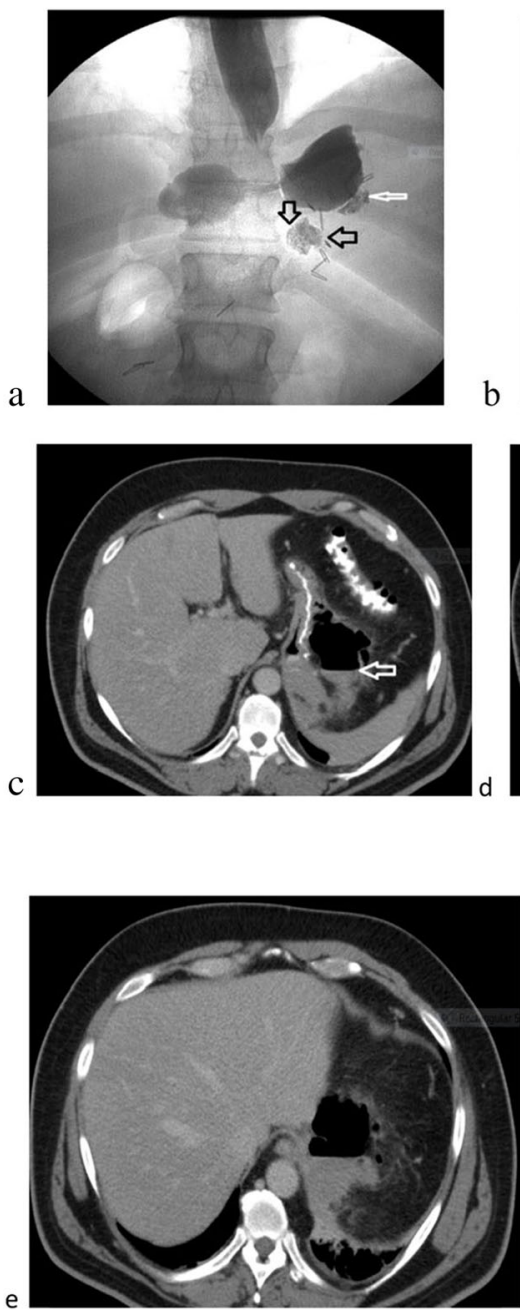

Fig. 9 A thirty-five-year-old female patient presented 3 days post-lap. sleeve gastrectomy by abdominal pain, fever, and tachycardia. a, b Upper gastrografin meal films revealed: free flow of contrast media through the esophagus with leakage of contrast media across the staple line. $\mathbf{c}-\mathbf{f}$ MSCT; axial and coronal reformatted images showed perigastric serpiginous air-filled tract seen extending from the left anterolateral aspect of the stomach adjacent to the surgical clips to the medial aspect of the left hepatic lobe associated with multiple gas bubbles under the diaphragm (pneumoperitoneum) together with increased perigastric fat density (inflammatory reaction) enables visualization of changes in the mesentery, such as stretching and rotation of vessels "swirl sign" and or engorgement of mesenteric vessels [33, 34]. (4) Intestinal obstruction may be caused by adhesions, internal hernias, anterior abdominal wall hernias, strictures at the jejunojejunal anastomosis, and, rarely, intussusceptions. (5) Intussusception typically occurs at or near the jejunojejunal anastomosis, with the staple line at this anastomosis presumably acting as the lead point for the intussusception [35]. (6) Gastroesophageal spasm.

\section{In cases of sleeve gastrectomy}

UGSI and C.T images were assessed for the presence of the following: (1) intraoperative organ injury, e.g., splenic injury. (2) Gastric leaks along the staple line, the leak
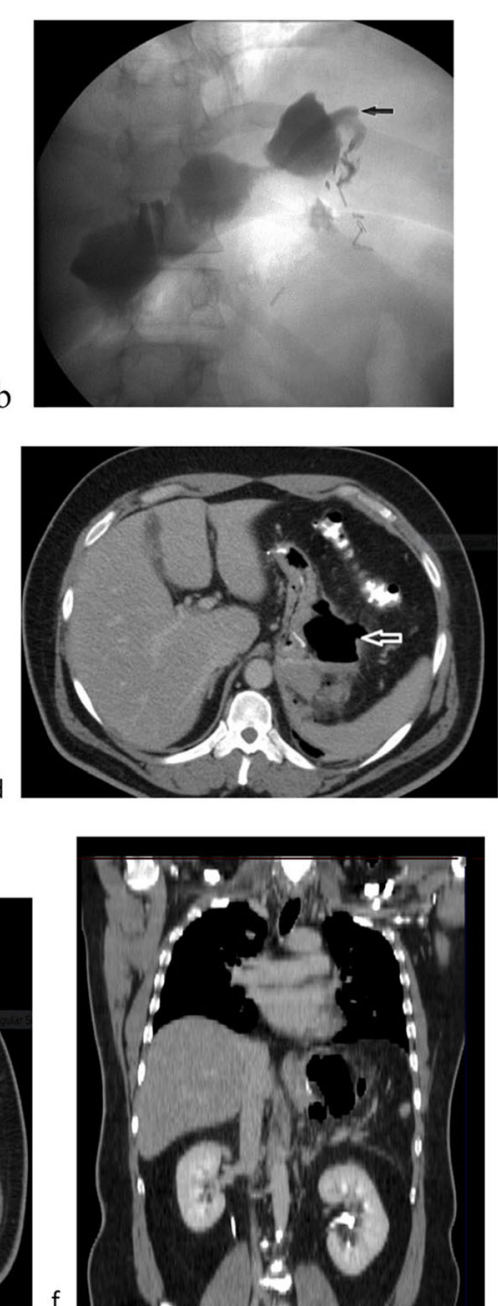

may be free or contained. A free leak was diagnosed if spillage of contrast was seen into the peritoneal cavity, whereas a contained leak was diagnosed on the extension of the contrast beyond the expected lumen. (3) Perigastric collection, hematoma, and hemoperitoneum. Acute hematoma has high attenuation values (40-60 $\mathrm{HU})$ Chronic hematoma may be difficult to distinguish from other fluid collections. (4) Presence of vascular affection, e.g., portal, splenic, and mesenteric vascular occlusion. (5) Abscess formation secondary to leak identified as high-density intraperitoneal fluid collection with rim enhancement that contains both gas and fluid. The presence of contrast material within the abscess after oral ingestion of contrast material confirms its origin. (6) Fistula formation: gastrocutaneous and gastrobronchial fistula secondary to subphrenic infection complicating 

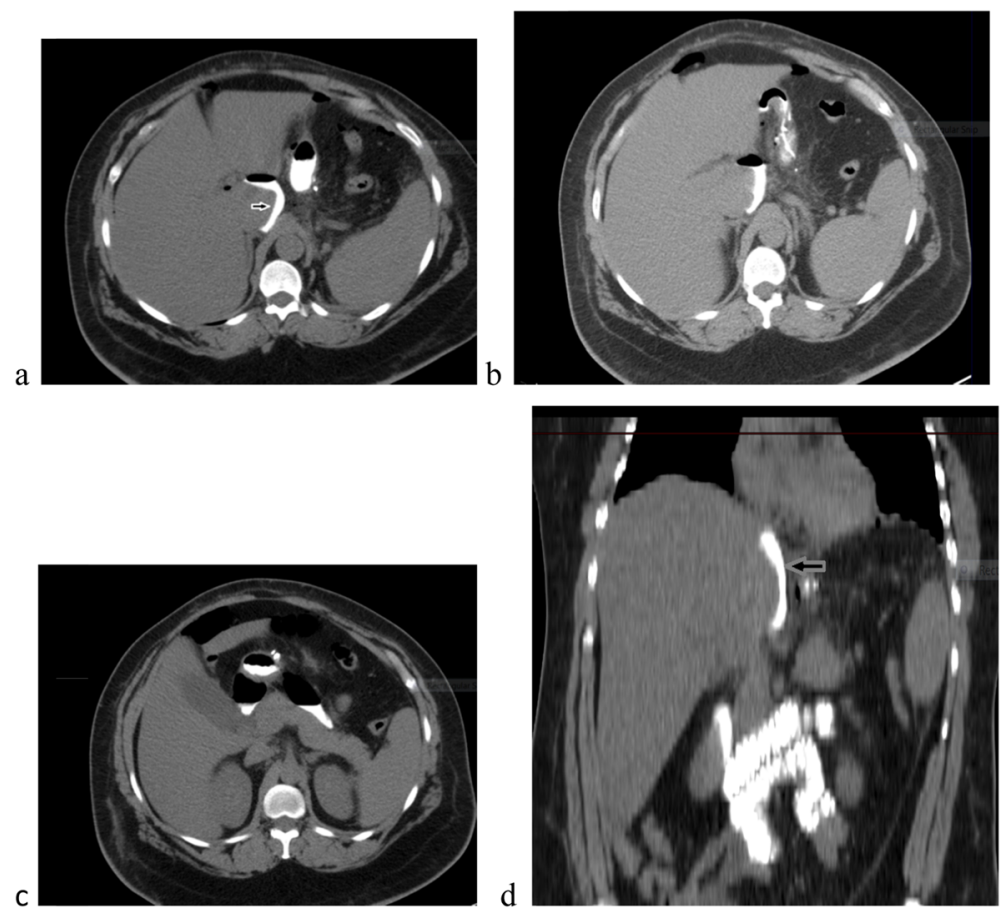

Fig. 10 A forty-five-year-old female patient presented 6 days post-lap. sleeve gastrectomy by abdominal pain and fever and tachycardia. a-c MSCT axial and $\mathbf{d}$ coronal reformatted images revealed evidence of leakage of the oral contrast noted; pooling around the caudate lobe with airfluid level associated with increased fat density noted in the vicinity of the stomach. UGSI shows no abnormality. Diagnosis: gastric leak post-LSG

staple line leak. CT may demonstrate the fistula, subphrenic abscesses, associated pleural effusion, and lung infection. (7) Strictures; gastric strictures may occur early, within a few days, secondary to ischemia or edema, or may occur later, usually as a result of fibrosis. Focal strictures or long segments of narrowing may occur when scarring occurs along the greater curvature staple line and barium studies may reveal focal strictures or long segments of narrowing with delayed emptying of barium from the residual stomach. (8) dilatation of gastric pouch. Barium studies may reveal the widening of the gastric sleeve, which no longer has a tubular appearance. (9) Incisional hernia. (10) Hiatus hernia $[15,23,32]$.

\section{Statistical analysis}

Data were analyzed using Statistical Program for Social Science (SPSS) version 20.0. Quantitative data were expressed as mean \pm standard deviation (SD). The following tests were done: (1) independent samples $t$ test of significance was used when comparing between two means. (2) A one-way analysis of variance (ANOVA) when comparing between more than two means. (3) Chi-square $\left(x^{2}\right)$ test of significance was used in order to compare proportions between two qualitative parameters. Probability ( $P$ value) $P$ value $<0.05$ was considered significant. $P$ value $<0.001$ was considered as highly significant. $P$ value $>0.05$ was considered insignificant.

\section{Results}

The sociodemographic variables and BMI of the 129 patients finally included in the study are shown in Table 1 and revealed no statistically significant difference regarding the age, gender, and BMI among the patients included in each type of surgery. Postoperative complications were detected in 113 patients as follows: 78 out of the 84 patients (92.8\%) who underwent sleeve gastrectomy (Table 2), 35 out of the 45 patients (77.7 \%) who underwent Roux-en-Y gastric bypass (Table 3). Early postoperative complications were defined as complications occurring within 30 days after surgery; late complications were defined as those occurring $>30$ days after surgery.

In patients who underwent Roux-en gastric bypass, the most common early postoperative complication was perigastric collection/hematoma (8.6\%) (Fig. 1) followed by leakage at the site of gastrojejunal anastomosis (5.7\%) (Figs. 2 and 3). The most common late postoperative complication was internal hernia (40\%) (Fig. 4), followed by an intestinal obstruction (17\%) (Figs. 5 and 6). The CT findings and management of these complications are summarized in Table 2 . The most common early postoperative complication of laparoscopic sleeve gastrectomy was 

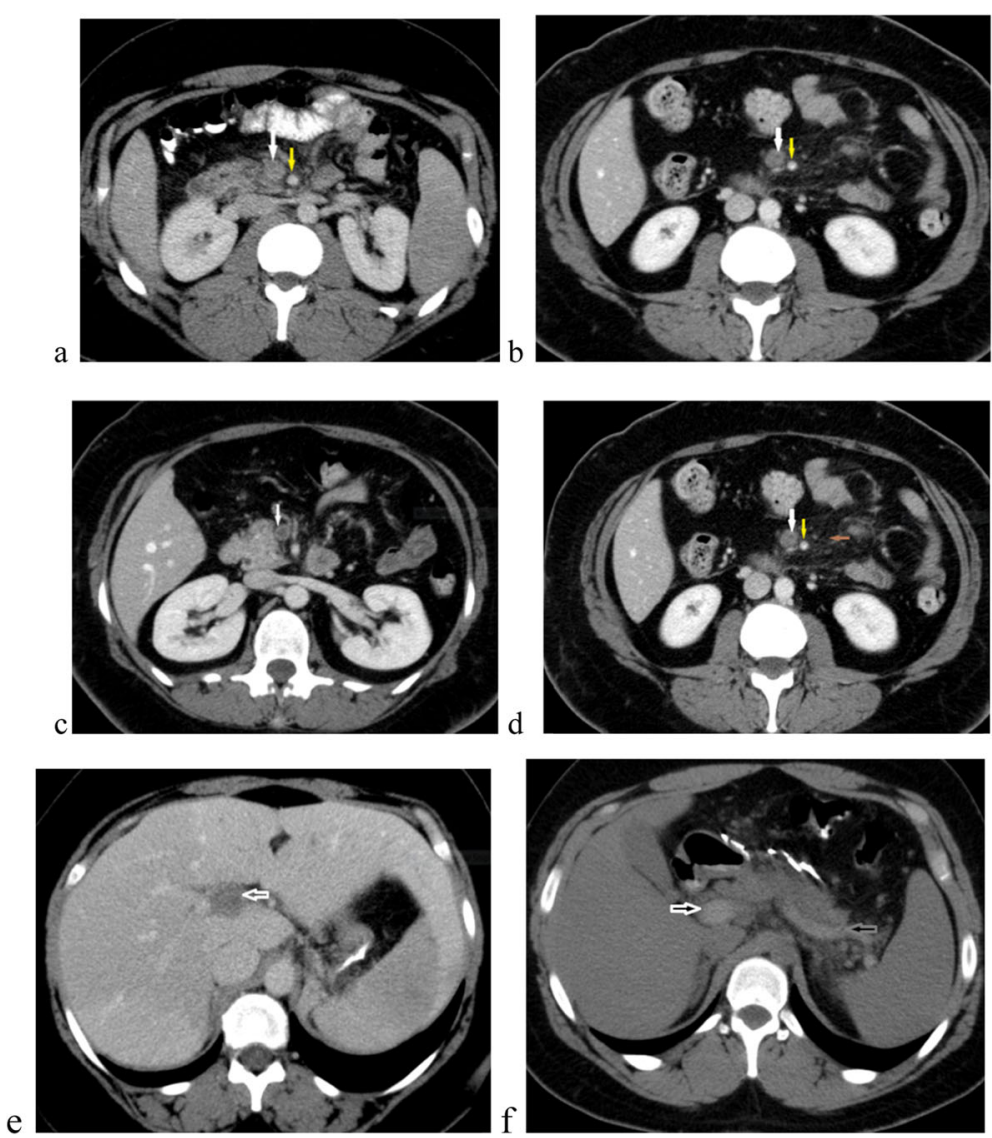

Fig. 11 A twenty-six-year-old male patient presented 1.5 years post-lap. sleeve gastrectomy by severe abdominal pain. a-d MSCT scans shows SMV thrombosis (white arrow). Note the normal SMA (yellow arrow) enhancement and ratio of SMV to SMA diameters $>2$ and increased density of the surrounding fat (brown arrow). Portal and splenic veins thrombosis post-LSG. e MSCT scan axial cut with IV contrast showing non-

enhanced portal vein (arrowed). f MSCT scan without intravenous contrast hyperattenuating splenic and portal vein. UGSI shows no abnormality. MSCT diagnosis: thrombosed portal, superior mesenteric and splenic vein

perigastric collection/hematoma (33.3\%) (Figs. 7 and 8) followed by leakage $23 \%$ (Figs. 9 and 10). The most common late postoperative complication was vascular thrombosis (13\%) (Fig. 11), followed by dilatation of gastric pouch (10\%) (Fig. 12). The CT findings and management of these complications are summarized in Table 3.

In the 35 symptomatic patients with RYGB complications, 6 complications (17\%) were diagnosed by both UGSI and C.T. abdomen and 29 complications (80\%) were diagnosed by C.T. only (Table 4). Statistically significant difference was found between UGIS and CT in diagnosis internal hernia, intestinal obstruction, and intussusception.

In the 78 symptomatic patients following post-sleeve gastrectomy, 29 complications (37.1\%) were diagnosed by both UGSI and C.T. abdomen (Fig. 13), 49 complications (62.8\%) were diagnosed by CT only (Fig. 14) (Table 5). Statistically significant difference was found between UGIS and CT in the detection of perigastric collection and hematoma, gastropancreatic abscess and portomesenteric thrombosis. UGSI were able to diagnose only 14 cases of leakage from stable line out of 18 cases, the 9 cases of increased size of gastric pouch, the 4 cases of hiatus hernia, 1 case of mid gastric sleeve stricture, 1 case of gastrobronchial fistula, and 1 case of mid gastric sleeve stricture and failed to diagnose the rest of complications which were diagnosed by CT only. Thus, CT was superior to or equivalent to UGSI in the detection of all sleeve gastrectomy and RYGB postoperative complications.

\section{Discussion}

During the past two decades, bariatric surgery has become an increasingly popular form of treatment for morbid obesity. The most common bariatric procedures performed include laparoscopic Roux-en-Y gastric bypass, laparoscopic sleeve gastrectomy, laparoscopic adjustable gastric banding, vertical-banded gastroplasty (VBG), jejunoileal bypass, biliopancreatic diversion, and biliopancreatic diversion with duodenal switch [23]. It is 


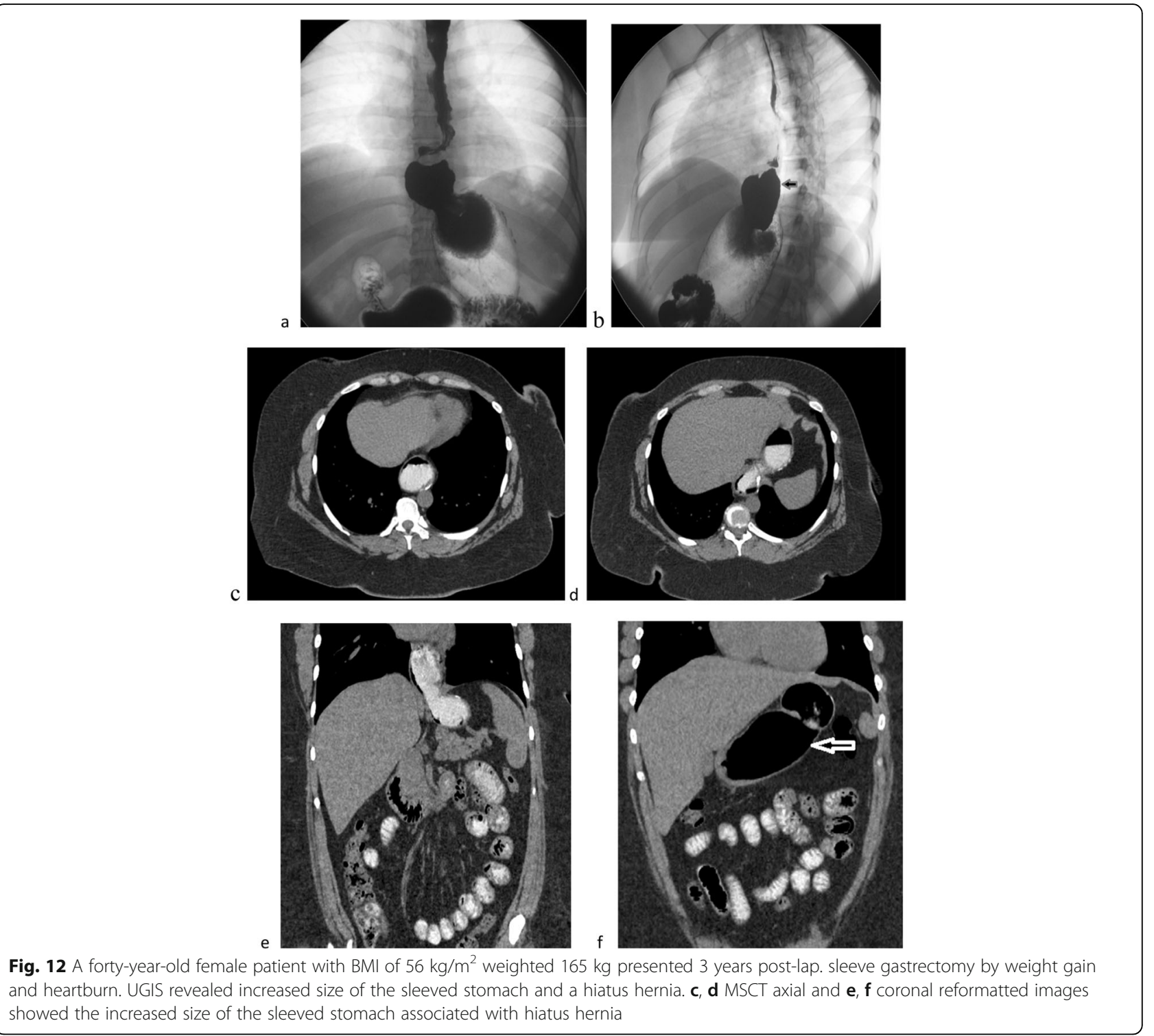

of ultimate importance to know the possible complications to allow prompt management, but unfortunately, physical examination of these patients is frequently impaired by obesity itself particularly in the postoperative period. Little is generally known about the role of imaging studies in the diagnosis of postoperative complications of bariatric surgery [24]. Fluoroscopic upper gastrointestinal examinations and abdominal computed tomography (CT) are the major imaging tests used to evaluate patients after bariatric surgery. In this prospective study, we investigated the value of contrast-enhanced MDCT in identifying postoperative complications of laparoscopic Roux-en-Y gastric bypass and laparoscopic sleeve gastrectomy in symptomatic patients.

According to multiple previous studies contrastenhanced CT imaging is considered the method of choice for investigation of abdominal symptoms, especially of patients undergoing gastric bypass [36-38]. Merckle et al. [39] reported that CT can provide a detailed view of the anatomy after Roux-en-Y gastric bypass. The positive oral contrast material administered just prior to image acquisition helps differentiate the gastric pouch and Roux limb from the excluded stomach and biliopancreatic limb, which are not opacified. For these authors, the afferent gastric distention occurring after Roux-en-Y gastric bypass can be due to obstruction or swelling of the enteroenterostomy and the imaging modality for this situation is the CT.

Carucci et al. stated that extraluminal leak is the most serious early complication of Roux-en-Y gastric bypass, occurring in up to $5 \%$ of patients within 10 days of surgery. Early detection is critical because of the risk of 
a
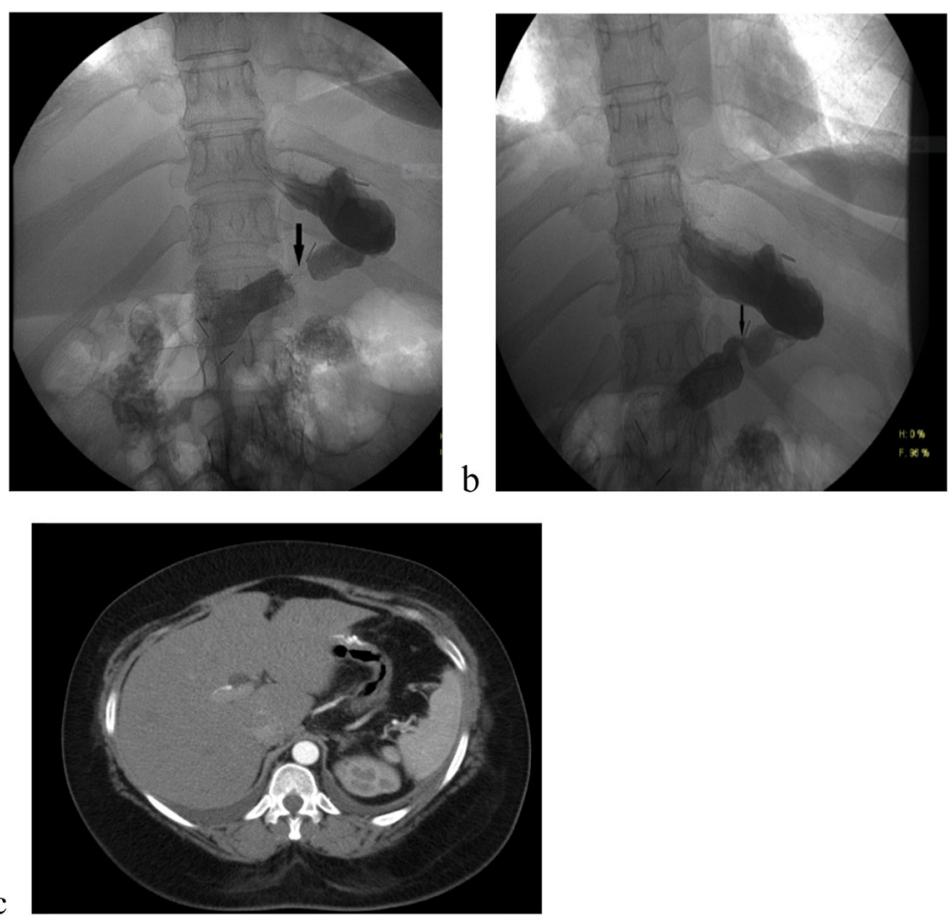

Fig. 13 A fifty-two-year-old male patient presented 1 year post-lap. sleeve gastrectomy by abdominal pain and vomiting. $\mathbf{a}$, b UGIS films showed stricture at mid-body of the stomach with delayed passage of the contrast at this part. c MSCT axial cuts show stricture of mid-sleeved stomach. Diagnosis: stricture of mid-sleeved stomach more evident in UGSI

a
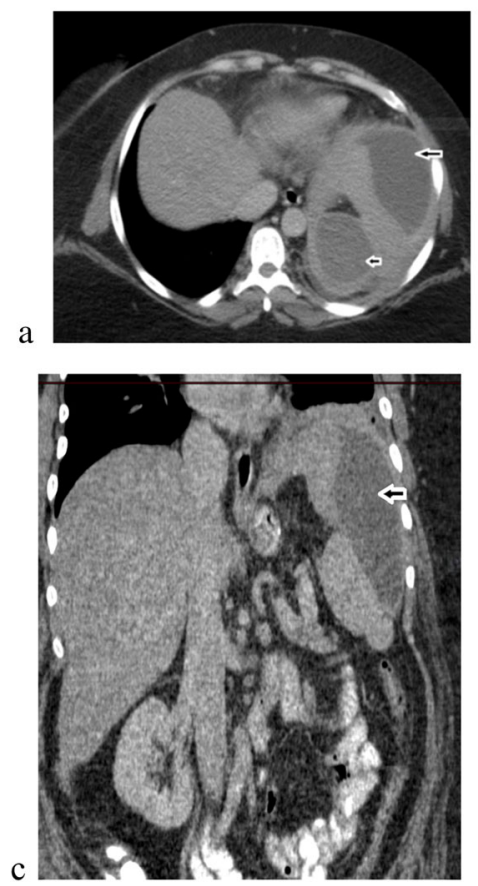
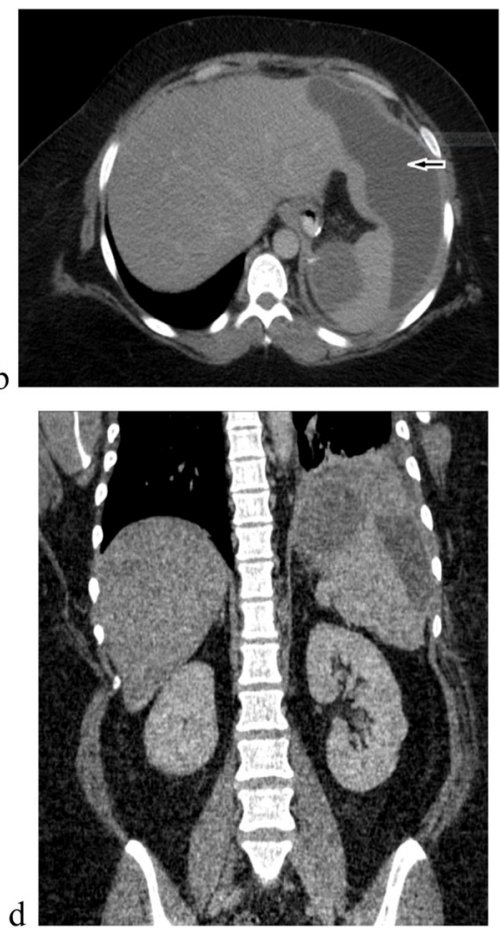

Fig. 14 A thirty-nine-year-old female patient with BMl of $48 \mathrm{~kg} / \mathrm{m}^{2}$ weighted $160 \mathrm{~kg}$ presented immediate post-lap. sleeve gastrectomy by severe abdominal pain and tachycardia. $\mathbf{a}, \mathbf{b}$ MSCT axial and $\mathbf{c}$, $\mathbf{d}$ coronal reformatted images showed an upper pole subcapsular hematoma and another encapsulated homogenous fluid adjacent to the lateral and superior aspect of the spleen extending superomedially to the left lobe of the liver anteriorly. UGSI shows no abnormality. MSCT diagnosis: upper pole subcapsular hematoma and another encapsulated subcapsular/perisplenic hematoma 
Table 4 Comparison of UGIS and CT in the detection of Roux-en-Y gastric bypass postoperative complications ( $N=35)$

\begin{tabular}{|c|c|c|c|c|c|c|}
\hline \multirow[t]{2}{*}{ Complication } & \multicolumn{2}{|c|}{ UGIS } & \multicolumn{2}{|l|}{$C T$} & \multicolumn{2}{|c|}{ Chi-square } \\
\hline & No. & $\%$ & No. & $\%$ & $x^{2}$ & P \\
\hline Leakage & 2 & 100.0 & 2 & 100.0 & 0.000 & 1.000 \\
\hline Perigastric collection and hematoma & 0 & 0.0 & 3 & 100.0 & 2.667 & 0.103 \\
\hline Internal hernia. & 0 & 0.0 & 14 & 100.0 & 24.143 & $<0.001$ \\
\hline Intestinal obstruction & 0 & 0.0 & 6 & 100.0 & 8.333 & 0.004 \\
\hline intussusception & 0 & 0.0 & 6 & 100.0 & 8.333 & 0.004 \\
\hline luminal narrowing & 1 & 100.0 & 1 & 100.0 & 0.000 & 1.000 \\
\hline Distended bowel and weight gain & 2 & 100.0 & 2 & 100.0 & 0.000 & 1.000 \\
\hline Gastroesophageal spasm & 1 & 100.0 & 1 & 100.0 & 0.000 & 1.000 \\
\hline
\end{tabular}

This table shows a statistically significant difference between UGIS and CT regarding to internal hernia, intestinal obstruction, and intussusception

abscess formation, peritonitis, and sepsis, with a mortality rate of more than $5 \%[25]$. The clinical symptoms of fever, tachycardia, abdominal pain, or an elevated WBC are often non-specific in the immediate postoperative period, and the physical examination may be limited by the large body habitus. The presence of tachycardia with a pulse exceeding 120 beats per minute has been reported to be the most consistent and reliable finding of peritonitis in bariatric patients [20]. Because of clinical difficulties in diagnosing postoperative leaks, some authors advocate routine upper GI examinations with water-soluble contrast agents 1-2 days after surgery as the preferred imaging test for ruling out leaks after gastric bypass surgery $[24,25]$. In accordance with these authors, the gastrojejunal anastomosis was the most common site of leak in our study occurring in $5.6 \%$. CT had greater sensitivity in detecting direct signs of fistula formation, namely, oral contrast extravasation and extraluminal gas, in assessing indirect signs as collections adjacent to the gastric pouch and free fluid in the abdominal cavity and in identifying complications as subphrenic abscess and peritonitis

Strictures at the gastrojejunal anastomosis may be caused by postsurgical scarring at the anastomosis or by chronic ischemia resulting from tension on the gastrojejunostomy [40]. Clinical presentation includes vomiting, bloating, and upper abdominal pain. Obstructive symptoms from strictures at the gastrojejunal anastomosis tend to develop shortly after meals, whereas vomiting associated with a small bowel obstruction may occur $1 \mathrm{~h}$ or more later. We identified a single case with gastrojujenal anastomotic strictures which were diagnosed on both

Table 5 Comparison of UGIS and CT in the detection of sleeve gastrectomy postoperative complications $(N=78)$

\begin{tabular}{|c|c|c|c|c|c|c|}
\hline \multirow[t]{2}{*}{ Complication } & \multicolumn{2}{|c|}{ UGIS } & \multicolumn{2}{|l|}{$\mathrm{CT}$} & \multicolumn{2}{|c|}{ Chi-square test } \\
\hline & No. & $\%$ & No. & $\%$ & $x^{2}$ & $P$ value \\
\hline 1-Liver contusion & 0 & 0.0 & 1 & 100.0 & 0.187 & 0.665 \\
\hline 2-Splenic tear & 0 & 0.0 & 2 & 100.0 & 0.444 & 0.505 \\
\hline 3-Leakage from stable line & 14 & 77.8 & 18 & 100.0 & 2.527 & 0.112 \\
\hline 4-Perigastric collection and hematoma & 0 & 0.0 & 26 & 100.0 & 48.077 & $<0.001$ \\
\hline 5-Gastropancreatic abscess & 0 & 0.0 & 1 & 100.0 & 0.187 & $<0.001$ \\
\hline 6-Gastrobronchial fistula & 1 & 100.0 & 1 & 100.0 & 0.000 & 1.000 \\
\hline 7-Rectus sheath hematoma & 0 & 0.0 & 2 & 100.0 & 0.444 & 0.505 \\
\hline 8-Portomesenteric thrombosis & 0 & 0.0 & 9 & 100.0 & 14.222 & $<0.001$ \\
\hline 9-Mid-gastric sleeve stricture & 1 & 100.0 & 1 & 100.0 & 0.000 & 1.000 \\
\hline 10-Incisional hernia & 0 & 0.0 & 1 & 100.0 & 0.187 & 0.665 \\
\hline 11-Increased size of gastric pouch & 9 & 100.0 & 9 & 100.0 & 0.000 & 1.000 \\
\hline 12-Hiatus hernia & 4 & 100.0 & 4 & 100.0 & 0.000 & 1.000 \\
\hline 13-Gastritis & 0 & 0.0 & 1 & 100.0 & 0.187 & 0.665 \\
\hline 14-S.C. seroma & 0 & 0.0 & 1 & 100.0 & 0.187 & 0.665 \\
\hline 15-Port site hernia & 0 & 0.0 & 1 & 100.0 & 0.187 & 0.665 \\
\hline
\end{tabular}


upper GIT studies and CT. Intestinal obstruction following RYGB may be the result of internal hernia, adhesions, jejunojejunal anastomotic stricture or rarely intussusception. Blachar et al. [24] believe that the combination of clinical and CT imaging findings may help distinguish the cause of bowel obstruction. Though adhesions are the most common cause of SBO after open Roux-en-Y gastric bypass, internal hernias are the most common cause after the laparoscopic form of surgery [37-39]. Small bowel obstruction resulting from internal hernias tend to appear longer periods after the operation and demonstrate the sign of mushroom aspect of the distended loops, accompanied by rotation of the mesenteric vessels. Internal hernia, intestinal obstruction, and intussusception were only identified on CT.

In patients who underwent LSG, the perigastric and intraperitoneal hematoma were the most common and most life-threatening early complications and required surgical management when the patients were hemodynamically unstable $[1,2]$. The second most common early complication was the dehiscence of sutures. Leaks most commonly occurred from the proximal end of the staple line just below the esophagogastric junction, followed by middle then lower thirds. They are usually manifested on UGIS by extravasation of watersoluble contrast material into extraluminal tracks or collections in the left upper quadrant. CT scans demonstrated the site of leakage as well as localized extraluminal collections or abscesses in this region. Two cases of splenic tears and a single case of liver contusion complicated surgery and a single gastrobronchial fistula and a single rectus sheath hematoma were detected in the early postoperative period. The cases complicated by portomesenteric vascular thrombosis were only diagnosed by CT. Gastric strictures developed when scarring along the greater curvature staple line causes marked narrowing of the pouch. Barium studies revealed focal or long narrowed segments with delayed emptying of barium from the residual stomach.

\section{Conclusion}

In conclusion, CE-MDCT is the imaging modality of choice in the diagnosis of major complications of RYGP and LSG. It can indirectly identify sutures dehiscence or perforation by the presence of pneumoperitoneum or free fluid. Also, the site of leakage can be directly identified by the administration of oral contrast. In patients operated through GBP, the presence of oral contrast in the excluded stomach is usually secondary to reflux and should not be mixed up with collections $[2,8,11,32]$. In cases of intestinal obstruction and internal hernia, IVCE-MDCT is able to identify the site of obstruction and rules out any associated complications.

\section{Abbreviations}

BMI: Body mass index; GBP: Gastric bypass; LSG: Laparoscopic sleeve gastrectomy; MDCT: Multidetector computed tomography; RYGB: Roux-en-Y gastric bypass; UGIS: Upper gastrointestinal contrast-enhanced study

\section{Acknowledgements}

The scientific guarantor of this publication is R.H.B. The authors of this manuscript declare no relationships with any companies whose products or services may be related to the subject matter of the article. No complex statistical methods were necessary for this paper.

\section{Authors' contributions}

$\mathrm{RHB}$ provided the main idea and the main design of the word, contributed in the acquisition, analysis, and interpretation of the imaging studies, have drafted the manuscript, revised and approved the submitted version, and agreed to be personally accountable for the author's own contributions and to ensure that questions related to the accuracy or integrity of any part of the work, even ones in which the author was not personally involved, are appropriately investigated, resolved, and the resolution documented in the literature. NAMC assisted in the collection of the clinical and pathologic data, contributed to the acquisition, analysis, and interpretation of the imaging studies, revised, and approved the submitted version. Both authors have read and approved the final manuscript.

\section{Funding}

The authors state that this work has not received any funding. Institutional Review Board approval was obtained.

\section{Availability of data and materials}

All datasets used and/or analyzed during the current study are available in the Radiology Department of El Salam International Hospital (Kuwait).

\section{Ethics approval and consent to participate}

The study was approved by the ethical committee of El Salam International Hospital (Kuwait) in December 2014 (no reference number was given at that time). Written consent for participation in the study was obtained from all patients or relatives of patients.

\section{Consent for publication}

Written informed consent for publication of the study was obtained from the patients themselves.

\section{Competing interests}

Both authors declare that they have no competing interests.

Received: 20 November 2019 Accepted: 27 November 2019 Published online: 04 February 2020

\section{References}

1. Friedenberg RM (2002) Obesity. Radiology 225:629-632

2. Peeters A, Barendregt JJ, Willekens F, Mackenbach JP, Al Mamun A, Bonneux L (2003) NEDCOM, the Netherlands Epidemiology and Demography Compression of Morbidity Research Group. Obesity in adulthood and its consequences for life expectancy: a life-table analysis. Ann Intern Med 138(1):24-32

3. Weiner $\mathrm{R}$, Bockhorn $\mathrm{H}$ et al (2001) A prospective randomized trial of different laparoscopic gastric banding techniques for morbid obesity. Surg Endosc 15:63-68

4. Capella JF, Capella RF (2002) An assessment of vertical banded gastroplastyRoux-en-Y gastric bypass for the treatment of morbid obesity. Am J Surg 183(2):117-123

5. Ribas FM, Nassif PA, Ribas CP, Dietz UA, Tuon F, Wendler E, Enokawa MS, Ferri KR (2012) Postoperative abdominal CT findings in patients submitted to Roux-en-y gastric bypass without ring. Rev Col Bras Cir 39(3):189-194

6. Spencer C, Guilherme M, Antonio C (2012) Imaging and bariatric surgery. AJR 190:122-135

7. Flum DR, Belle SH, King WC (2009) et al; Longitudinal assessment of bariatric surgery (LABS) consortium. Perioperative safety in the longitudinal assessment of bariatric surgery. N Engl J Med 361(5):445-454 
8. Winter TG, Ager JD, Nghiem HV et al (2004) Upper gastrointestinal tract abdomen: Water as an orally administered contrast agent for helical CT. Radiology 201:365-370

9. Dhahri A, Qassemyar Q, Verhaeghe P, Desailloud-Godard R, Badaoui R, Regimbeau JM (2009) Bariatric surgery in the treatmentof severe obesity. Rev Prat 59:1198-1203

10. Cummings DE, Overduin J, Foster-Schubert KE (2004) Gastric bypass for obesity: mechanisms of weight loss and diabetes resolution. J Clin Endocrinol Metab 89(6):2608-2615

11. Ogden CL, Carroll MD, Curtin LR, McDowell MA, Tabak CJ, Flegal KM (2006) Prevalence of overweight and obesity in the United States, 1999-2004. JAMA 295(13):1549-1555

12. Nguyen NT, Ho HS, Mayer KL, Palmer L, Wolfe BM (1999) Laparoscopic Roux-en-Y Gastric Bypass for Morbid Obesity. JSLS 3(3):193-196

13. Scheirey CD, Scholz FJ, Shah PC, Brams DM, Wong BB, Pedrosa M (2006) Radiology of the laparoscopic Roux-en-Y gastric bypass procedure: conceptualization and precise interpretation of results. RadioGraphics 26(5): 1355-1371

14. Shah S, Shah V, Ahmed AR, Blunt DM (2011) Imaging in bariatric surgery: service set-up, post-operative anatomy and complications. Br J Radiol 84(998):101-111

15. Levine MS, Carucci LR (2014) Imaging of bariatric surgery. Normal Anatomy and Postoperative Complications. Radiology 270(2):327-341

16. Gumbs AA, Gagner M, Dakin G, Pomp A (2007) Sleeve gastrectomy for morbid obesity. Obes Surg 17(7):962-969

17. Higa KD, Boone KB, Ho T, Davies OG (2000) Laparoscopic Roux-en-Y gastric bypass for morbid obesity: technique and preliminary results of our first 400 patients. Arch Surg. 135(9):1029-1033 discussion 1033-4

18. Ma IT, Madura JA (2015) Gastrointestinal complications after bariatric surgery. Gastroenterol Hepatol. 11:526-535

19. Hernández J, Boza C (2016) Novel treatments for complications afterbariatric surgery. Ann Surg Innov Res. 10:3

20. Buckwalter JA, Herbst CA Jr (1988) Leaks occurring after gastric bariatric operations. Surgery 103:156-160 33.Kellogg TA, Swan T, Leslie DA, et al. Patterns of readmission and reoperation within 90 days after Roux-en-Y gastric bypass. Surg Obes Relat Dis 2009;5:416-23

21. Saunders J, Ballantyne GH, Belsley S et al (2008) One-year readmission rates at a high volume bariatric surgery center : laparoscopic adjustable gastric banding, laparoscopic gastric bypass, and vertical banded gastroplastyRoux-en-Y gastric bypass. Obes Surg 18:1233-1240

22. Greestein AJ, O'Rourke RW (2011) Abdominal pain after gastric bypass : suspects and solutions. Am J Surg 201:819-827

23. Chandler RC, Srinivas G, Chintapalli KN, Schwesinger WH, Prasad SR (2008) Imaging in bariatric surgery: a guide to postsurgical anatomy and common complications. Am J Roentgenol. 190:122-35.11

24. Blachar A, Federle MP, Pealer KM, Ikramuddin S, Schauer PR (2002) Gastrointestinal complications of laparoscopic Roux-en-Y gastric bypass surgery: clinical and imaging findings. Radiology 223(3):625-632

25. Carucci LR, Turner MA, Conklin RC, DeMaria EJ, Kellum JM, Sugerman HJ (2006) Roux-en-Y gastric bypass surgery for morbid obesity: evaluation of postoperative extraluminal leaks with upper gastrointestinal series. Radiology 238(1):119-127

26. Carucci LR, Turner MA, Shaylor SD (2009) Internal hernia following Roux-en$Y$ gastric bypass surgery for morbid obesity: evaluation of radiographic findings at small-bowel examination. Radiology 251(3):762-770

27. Cucchi SG, Pories WJ, MacDonald KG, Morgan EJ (1995) Gastro-gastric fistulas. A complication of divided gastric bypass surgery. Ann Surg 221:387-391

28. Sanyal AJ, Sugerman HJ, Kellum JM et al (1992) Stomal complications of gastric bypass: Incidence and outcome of therapy. Am J Gastroenterol 87: 1165-1169

29. Filho AJB, Kondo W, Nassif S et al (2006) Gastrogastric fistula : a possible complication of Roux-en-Y gastric bypass. JSLS 10:326-331

30. Husain S, Ahmed AR, Johnson J et al (2007) Small-bowel obstruction after laparoscopic Roux-en-Y gastric bypass : etiology, diagnosis, and management. Arch Surg 142:988-993

31. Stephenson D, Moon RC, Teixeira AF, Jawad MA (2014) Intussusception after Roux-en-Y gastric bypass. Surg Obes Relat Dis 10:666-670

32. Chivot B, Roberta N, Lafayea D, Fuksb A, Dhahrib P, Verhaegheb J-M, Regimbeaub T, Yzeta T (2013) Laparoscopic sleeve gastrectomy: Imaging of normal anatomic features and postoperative gastrointestinal complications. Diagn Interv Imaging 94:823-834
33. Carucci LR, Turner MA, Yu J (2007) Imaging evaluation following Rouxen-Y gastric bypass surgery for morbid obesity. Radiol Clin North Am 45(2):247-260

34. Lockhart ME, Tessler FN, Canon CL et al (2007) Internal hernia after gastric bypass: sensitivity and specificity of seven $\mathrm{CT}$ signs with surgical correlation and controls. AJR Am J Roentgenol 188(3):745-750

35. Duane TM, Wohlgemuth S, Ruffin K (2000) Intussusception after Roux-en-Y gastric bypass. Am Surg 66(1):82-84

36. Labrunie EM, Marchiori E (2007) Obstruçpo intestinal p sgastroplastia redutora pela técnica de higa para tratamento da obesidade $m$ rbida: aspectos por imagem. Radiol Bras 40(3):161-165

37. Parakh S, Soto E, Merola S (2007) Diagnosis and management of internal hernias after laparoscopic gastric bypass. Obes Surg. 17(11):1498-1502

38. Srikanth MS, Keskey T, Fox SR, Oh KH, Fox ER, Fox KM (2004) Computed tomography patterns in small bowel obstruction after open distal gastric bypass. Obes Surg. 14(6):811-822

39. Merkle EM, Hallowell PT, Crouse C, Nakamoto DA, Stellato TA (2005) Rouxen-Y gastric bypass for clinically severe obesity: normal appearance and spectrum of complications at imaging. Radiology. 234(3):674-683

40. Spaulding $L$ (1997) The impact of small bowel resection on the incidence of stomal stenosis and marginal ulcer after gastric bypass. Obes Surg 7(6):485-487 discussion 488

\section{Publisher's Note}

Springer Nature remains neutral with regard to jurisdictional claims in published maps and institutional affiliations.

\section{Submit your manuscript to a SpringerOpen ${ }^{\circ}$ journal and benefit from:}

- Convenient online submission

- Rigorous peer review

- Open access: articles freely available online

- High visibility within the field

- Retaining the copyright to your article

Submit your next manuscript at $>$ springeropen.com 